\title{
Development of Some Larval Nematodes in Experimental and Natural Animal Hosts: An Insight into Development of Pathological Lesions vis-a-vis Host-Parasite Interactions
}

\author{
N. Chowdhury, ${ }^{1}$ N. K. Sood, ${ }^{2}$ Shyam Lal, ${ }^{1}$ Kuldip Gupta, ${ }^{2}$ and L. D. Singla ${ }^{1}$ \\ ${ }^{1}$ Department of Veterinary Parasitology, College of Veterinary Science, Guru Angad Dev Veterinary and Animal Sciences University, \\ Ludhiana, Punjab 141004, India \\ ${ }^{2}$ Department of Veterinary Pathology, College of Veterinary Science, Guru Angad Dev Veterinary and Animal Sciences University, \\ Ludhiana, Punjab 141004, India
}

Correspondence should be addressed to N. Chowdhury; drnchowdhury@yahoo.com

Received 31 August 2013; Accepted 9 October 2013

Academic Editors: A. Casulli and R. Toledo

Copyright (C) 2013 N. Chowdhury et al. This is an open access article distributed under the Creative Commons Attribution License, which permits unrestricted use, distribution, and reproduction in any medium, provided the original work is properly cited.

\begin{abstract}
Infective third-stage larvae of three spiruroid nematodes, Ascarops strongylina and Physocephalus sexalatus of pigs and Spirocerca lupi of dogs, were recovered from 14 species of coprophagous beetles belonging to 4 different genera. These larvae were fed to rabbits and/or guinea pigs to study their development in these experimental hosts. Larvae of A. strongylina reached the adult stage in all rabbits and one guinea pig. The adult worms recovered in these hosts were $40 \%$ and $4 \%$, respectively, and became diminutive in comparison to their natural hosts. The larvae of $P$. sexalatus became reencysted in the gastric wall of rabbits inducing marked pathological changes. The infective larvae of $S$. lupi became reencapsulated in the stomach wall of the rabbit and also showed development in the aortic wall. Adults of Toxocara canis of dog, collected from 5 different regions of the Indian subcontinent, varied significantly in size. The mouse passage of infective larvae of one of these types led to the recovery of the adults from the experimental dogs that were smaller in size and caused severe pathology in natural experimental hosts. Developmental effects shown in experimental hosts and host specificity are of value in understanding the evolution of nematode parasitism.
\end{abstract}

\section{Introduction}

Host-parasite interactions by parasitism remained unexplained till 20th century. Graham Bell and Austin Bert from Canada hypothesized the term, "a recombination, favoured by antagonistic" coevolution between the host and the parasite [1]. It was further defined as the resultant product of ecological, sociological, and physiological causes [2]. The phenomenon not only increased the parasite's reproductive capacity but also enhanced its virulence and/or pathogenicity. Host specificity, on the other hand, is the result of coaccommodation between the two, that is, the host and the parasite. The nature of the parasite, ambient conditions, and the host infected are the key factors determining the outcome of such a relationship in terms of virulence, pathogenicity, reproductive potential, maturity of the parasite, and finally the response of the host. In this communication, experimental results on development of some larval nematodes in natural and experimental animal hosts have been discussed in connection to host-parasite relationship.

\section{Materials and Methods}

The infective third-stage larvae $\left(\mathrm{L}_{3}\right)$ of the spiruroid nematodes (Table 1) were obtained from 14 species of naturallyinfected coprophagous beetles belonging to 4 different genera. The larvae were studied under coverslip preparation and identified as described by Alicata [3], Porter [4], Watanabe [5], and Ryzhikov and Nazarova [6]. In all experiments, the infective larvae were administered with the help of a stomach tube to the experimental and natural hosts, namely, rabbit, 


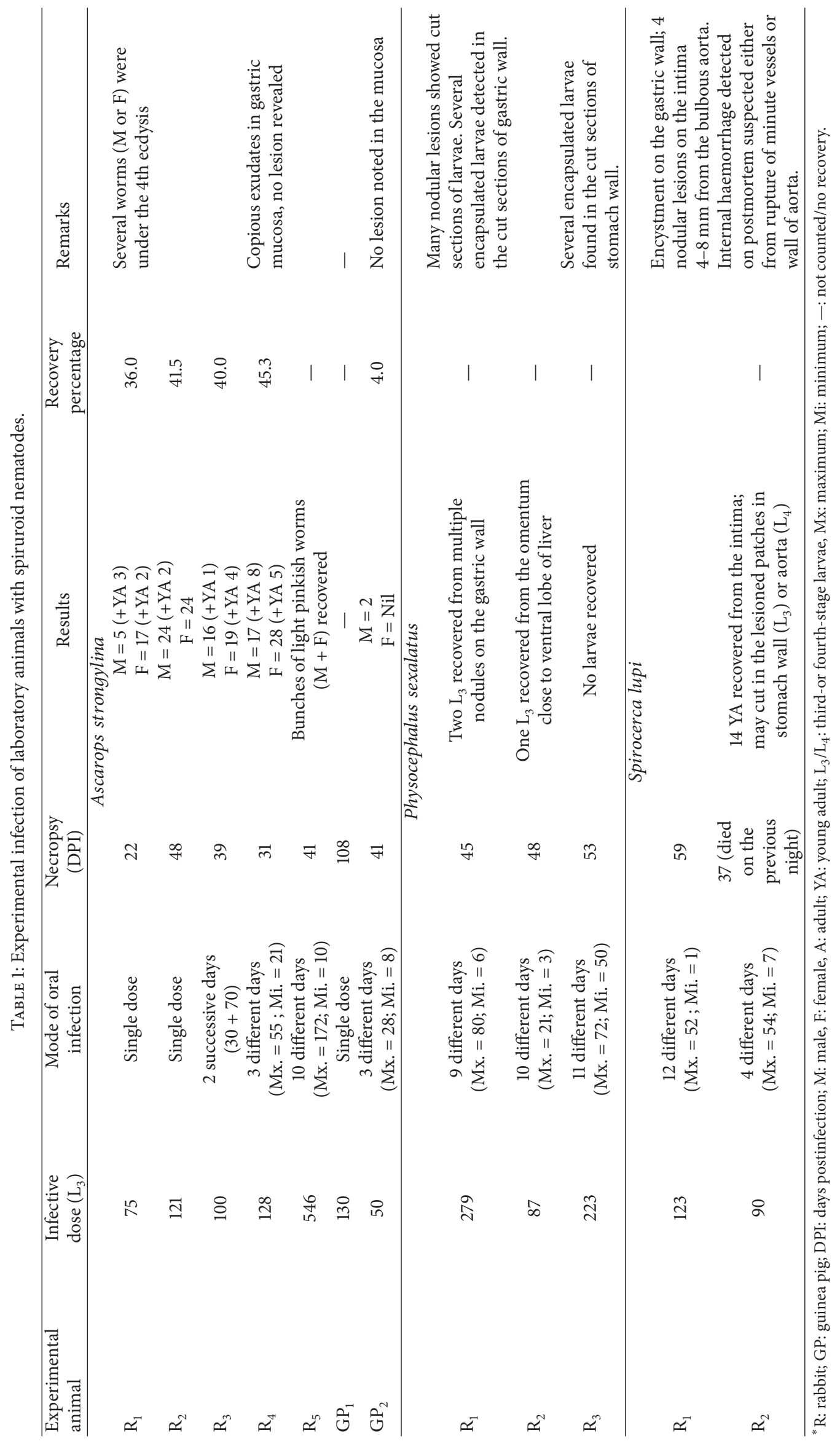


TABLE 2: Toxocara canis: host related effect between large, medium, and small types.

\begin{tabular}{lccr}
\hline Type & Length & Diameter & Volume/area \\
\hline Large $(n=2)$ & $17.45 \pm 0.65^{\mathrm{a} * *}$ & $2.2 \pm 0.00^{\mathrm{a} * *}$ & $38.39 \pm 1.43^{\mathrm{a} * *}$ \\
Medium $(n=4)$ & $11.30 \pm 0.49^{\mathrm{b} * *}$ & $1.85 \pm 0.12^{\mathrm{a} * *}$ & $20.93 \pm 1.73^{\mathrm{b} * *}$ \\
Small $(n=8)$ & $7.01 \pm 0.77^{\mathrm{c} * *}$ & $1.10 \pm 0.07^{\mathrm{b} * *}$ & $7.80 \pm 1.06^{\mathrm{c} * *}$ \\
Overall $(n=14)$ & $9.73 \pm 1.11$ & $1.10 \pm 0.07$ & $15.92 \pm 3.09$ \\
\hline
\end{tabular}

All specimens in Tables 2 and 3 are gravid females; length expressed in $\mathrm{cms}$ and diameter in mm. Means within a column with different superscript differing significantly $\left({ }^{* *} P<0.01\right)$.

TABLE 3: Toxocara canis: Host related effect between local (Ludhiana) versus passage (Assam type).

\begin{tabular}{lccc}
\hline Type & Length & Diameter & Area \\
\hline Ludhiana $n=2$ & $7.65 \pm 0.25$ & $1.50 \pm 0.00$ & $11.47 \pm 0.38$ \\
Passage $n=2$ & $6.70 \pm 0.40$ & $0.90 \pm 0.10$ & $6.07 \pm 1.03$ \\
$F$ value & 4.056 & $36.00^{*}$ & $24.31^{*}$ \\
Overall $n=4$ & $7.12 \pm 0.34$ & $1.20 \pm 0.18$ & $8.77 \pm 1.62$ \\
\hline
\end{tabular}

Significance level $P<0.05$.

TABle 4: Development of Toxocara canis in pups/dogs (mouse passage of $\mathrm{L}_{2}$ ).

\begin{tabular}{lcccc}
\hline \multirow{2}{*}{$\begin{array}{l}\text { Age in months } \\
\text { and sex }\end{array}$} & Necropsy & \multicolumn{2}{c}{ Recovery of adults } & Percentage \\
\hline 3 female & 58 & 33 & 35 & 22.6 \\
2.5 female & 58 & 03 & 07 & 3.3 \\
3 female & 57 & 46 & 42 & 29.3 \\
2.5 female & 89 & 02 & 10 & 4.0 \\
2 male & $26($ died $)$ & - & - & - \\
3 male & 45 & 37 & 47 & 28.0 \\
3 male & 58 & - & - & - \\
2.5 female & 47 & 07 & 09 & 5.3 \\
\hline
\end{tabular}

guinea pig, mice, or pups. During this study, unidentified larvae recovered from the beetle hosts were fed to 2 rabbits.

The differently-developed juveniles/larvae collected from viscera of the animals were studied alive and from the preserved specimens after appropriate clearing. The tissues showing conspicious gross lesions were fixed in 10\% formalin and serially-cut into $5-6 \mu \mathrm{m}$ thick paraffin sections and stained with haematoxylin and eosin for histopathological evaluation.

The female specimens of Toxocara canis collected either in physiological saline or $10 \%$ formalin (Tables 2 and 3 ) were obtained either locally from pups/dogs or were received by us from 4 different cities in Assam, Gujarat, M.P., and U.P. located at a distance of $800-2,500 \mathrm{kms}$ from Ludhiana, Punjab, India

For mouse passage, 12 albino mice were administered 100 second stage larvae (Table 4) at fortnightly interval, for a period of 1.5 months. The deskinned mice cut into pieces, were fed to 8 pups/dogs (one mouse each) no earlier than two months postinfection. The animals were maintained as per Institutional Animal Ethics Committee Guidelines. The data

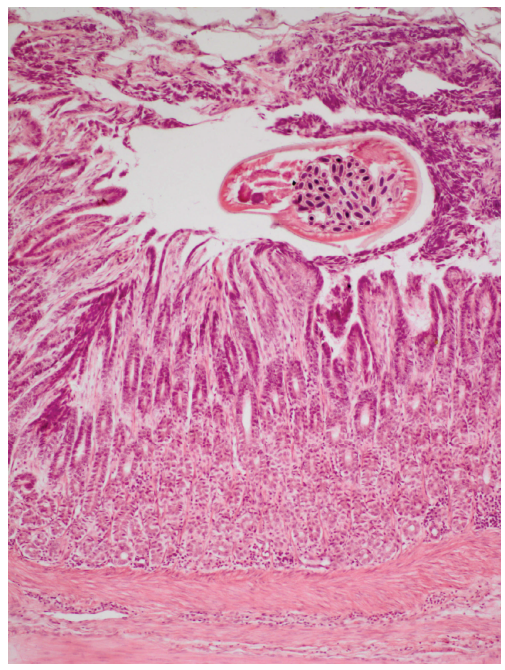

FIGURE 1: Photograph of stomach of rabbit showing a gravid female of A. strongylina cut transversely towards the lumen. Note denudation of superficial lining of epithelium (H. E. original magnification $\times 100 \mathrm{X})$.

were analysed using SPSS 16.0 version by one-way analysis of variance and the means were compared by Tukey's b and Duncan's Multiple Range Test.

\section{Results}

The distinctive development patterns of the three spiruroid nematodes including two stomach worms of pig, that is, Ascarops strongylina and Physocephalus sexalatus and the third, the oesophageal worm of dog, that is, Spirocerca lupi are depicted in Table 1. The experimental infection of $A$. strongylina in rabbit and guinea pigs showed a marked difference in development and recovery of the parasite. Microscopically, the pathological lesions in A. strongylina consisted of damage by the adults and juveniles to the lining 


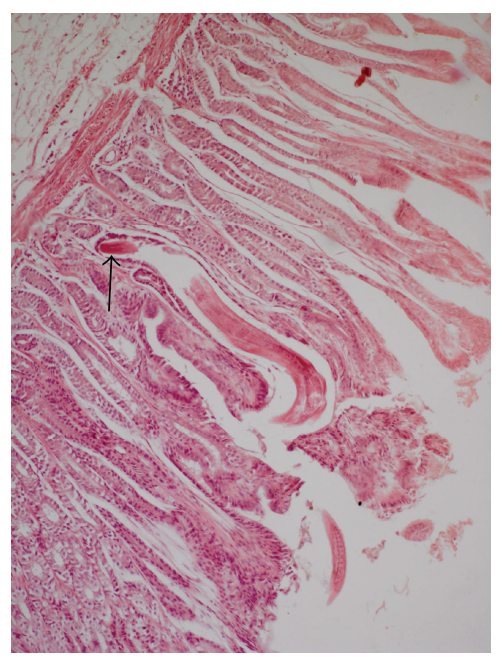

FIGURE 2: Section of stomach of rabbit showing a juvenile $A$. strongylina longitudinally cut deep into the mucosa. Arrow indicates head end of the $\mathrm{L}_{4}(\mathrm{H}$. E. original magnification $\times 100 \mathrm{X})$.

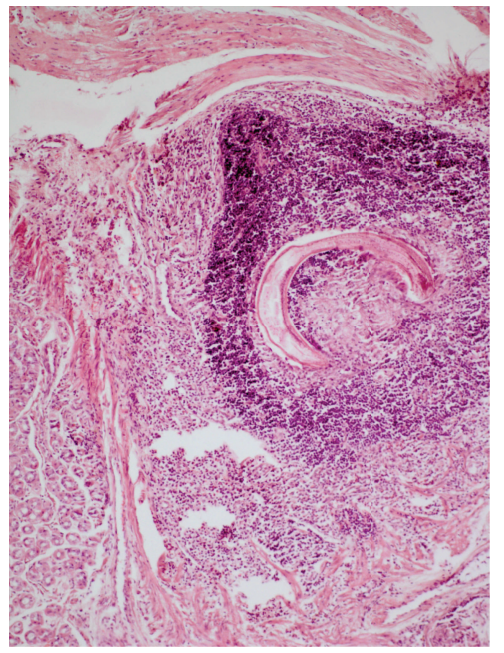

FIgURE 3: Section of stomach of a rabbit with the longitudinally cut larva of $P$. sexalatus in the submucosa; parasite is surrounded by a large rim of inflammatory cells-lymphocytes, eosinophils, and connective tissue $(\mathrm{H}$. E. original magnification $\times 100 \mathrm{X})$.

of mucosa and destruction of the underlying glands by the young adults that reached nearly the base of the mucosa (Figures 1 and 2).

In contrast to A. strongylina, $P$. sexalatus showed poor development and recovery in infected rabbits. In one rabbit, a third-stage larva was found that had migrated to the omentum (Table 1), whereas in two other animals, $\mathrm{L}_{3}$ remained arrested mostly in the gastric wall and encapsulated in different layers without undergoing further development. The encapsulated juveniles were found in the mucosal, submucosal, and muscular coats (Figures 3 and 5) of the gastric wall. The nodular lesions revealed the parasites surrounded by necrotic debris, neutrophils, and activated macrophages. At the periphery of such lesions, the inflammatory reaction

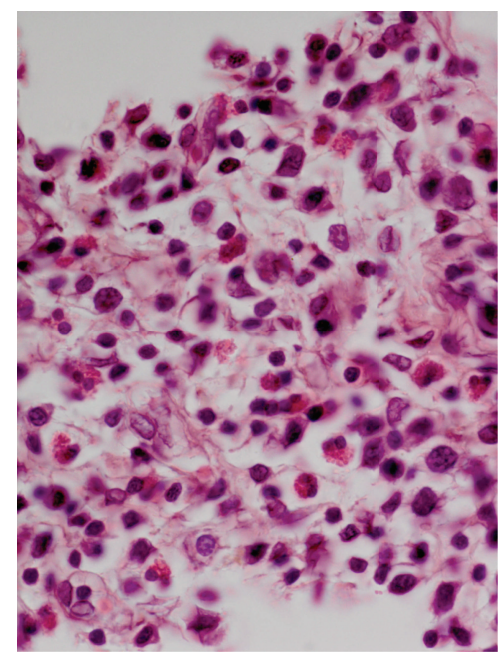

FIGURE 4: Higher magnification of Figure 3 showing more conspicuous eosinophils, macrophages, and a few fibroblasts among inflammatory cells $(\mathrm{H}$. E. original magnification $\times 400 \mathrm{X})$.

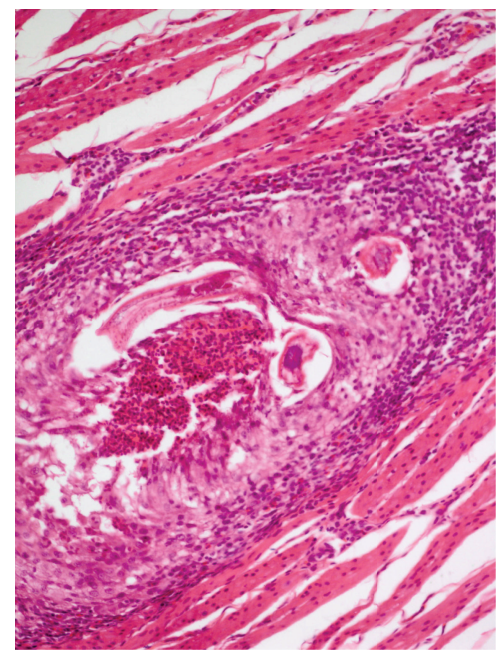

FIGURE 5: Parasitic granuloma in the tunica muscularis of stomach with chronic inflammatory cells including fibroblasts and cut sections of $P$. sexalatus surrounded by an adjacent zone of necrosis $(\mathrm{H}$. E. original magnification $\times 100 \mathrm{X}$ ).

consisted of lymphocytes, macrophages, and eosinophils, while in the areas adjacent to the mucosa, there were aggregates of macrophages and lymphocytes (Figure 4).

The unidentified larvae did not develop in any of the rabbits, rather they became reencapsulted in the submucosa (Figure 6). Adjacent to the sections of this parasite, chronic inflammatory response consisted of necrosis and dystrophic calcification, surrounded by extensive fibroplasia and eosinophils.

In two experimental rabbits, the $\mathrm{L}_{3}$ of $S$. lupi were found, not only reencapsulated in the gastric wall, but some of the infective larvae were seen to have migrated to the aorta causing typical lesion of "aortic spirocercosis." The recovered larvae from the gastric wall of the rabbits measured: $2.18 \mathrm{~mm}$ 


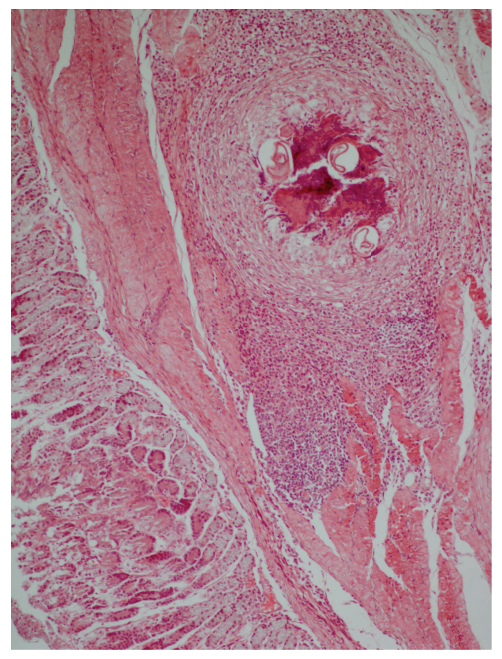

FIGURE 6: Sections of stomach showing an old parasitic granuloma of an unidentified larva and chronic inflammatory changes along with necrosis, fibrosis, and dystrophic calcification surrounded by a distinct fibrous encapsulation (H. E. original magnification $\times 100 \mathrm{X})$.

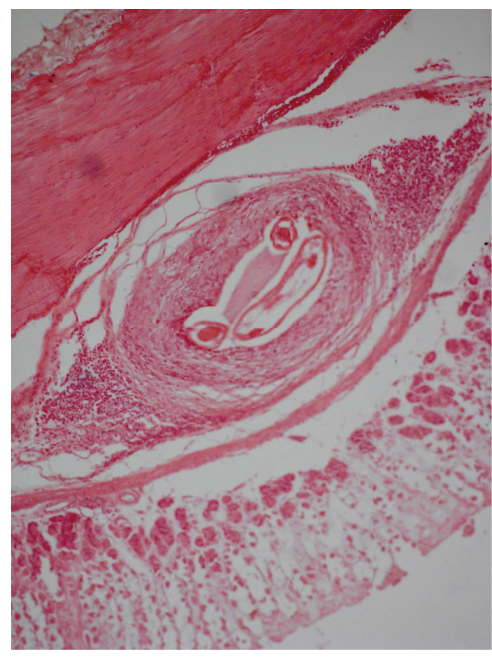

FIGURE 7: A section of stomach rabbit showing chronic granuloma around $S$. lupi in the submucosa with extensive fibrosis around the parasite and a peripheral zone of chronic inflammatory cells (H. E. original magnification $\times 100 \mathrm{X}$ ).

$\times 0.093 \mathrm{~mm}-2.52 \mathrm{~mm} \times 0.097$, which falls in the range of $\mathrm{L}_{3}$ recovered from the dung-beetles $(2.19 \mathrm{~mm} \times 0.085-2.48 \mathrm{~mm}$ $\times 0.12 \mathrm{~mm}$ ). Interestingly, the young adults recovered from the aorta measured: $2.58 \mathrm{~mm} \times 0.17-5.29 \mathrm{~mm} \times 0.21 \mathrm{~mm}$.

The histopathology of the lesions from the stomach wall revealed oedema of the gastric mucosa and a zone of necrosis, surrounded by extensive inflammation, consisting predominantly of macrophages, lymphocytes, and some eosinophils. Early fibroblastic proliferation was also evident. Around the parasite in the submucosa, activated macrophages were found surrounded by lymphocytes, eosinophils, and mature collagen fibres (Figure 7).

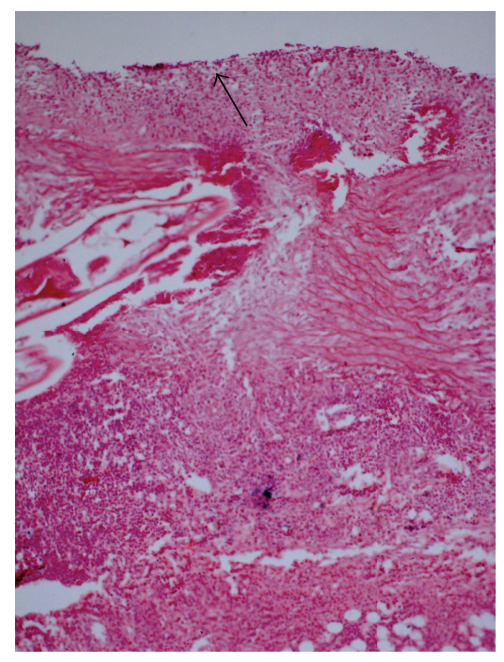

FIGURE 8: Section of aorta of a rabbit with a longitudinally cut section of $S$. lupi in media. Note the extensive tissue damage, necrotic debris in the parasitic tunnels/cavities, fragmented tunica elastica interna, and marked infiltration of inflammatory cells. Arrow indicates intima (H. E. original magnification $\times 100 \mathrm{X}$ ).

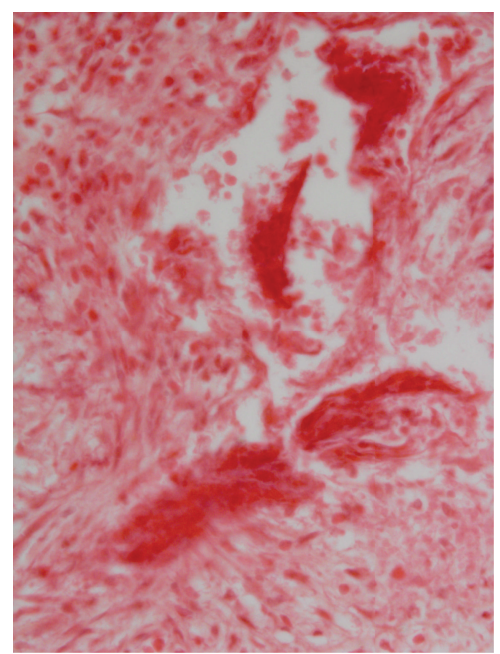

FIGURE 9: A section of chronically-infected aorta with S. lupi in the intimal region showing parasite remnants in dystrophic calcification surrounded by fibroblastic reaction within tunica intima $(H$. E. original magnification $\times 400 \mathrm{X})$.

In the aorta, the three layers depicted varying grades of changes. The intima was greatly thickened owing to proliferation of fibro-cellular tissue (Figure 9). The endothelial lining was disrupted and internal elastic lamina was fragmented (Figure 8). In the parasitic tunnels, a hyalinised necrosed thin layer was surrounded by connective tissue proliferation and inflammatory response, predominantly consisting of lymphocytes and eosinophils, a few plasma cells, and macrophages. In the media, there was a marked infiltration of eosinophils, many plasma cells, some lymphocytes, and a few macrophages (Figure 10). In the outer media, serofibrinous exudation was observed, in addition to necrotic foci having 


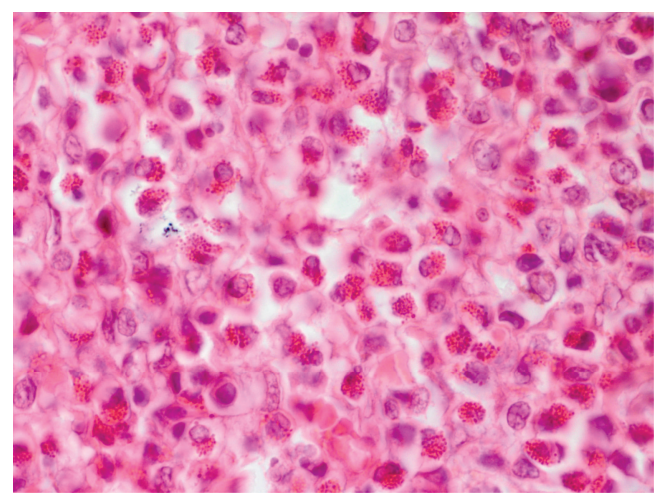

FIgURE 10: Section of another aorta infected with S. lupi depicting marked infiltration of eosinophils and plasma cells $(\times 400)$.

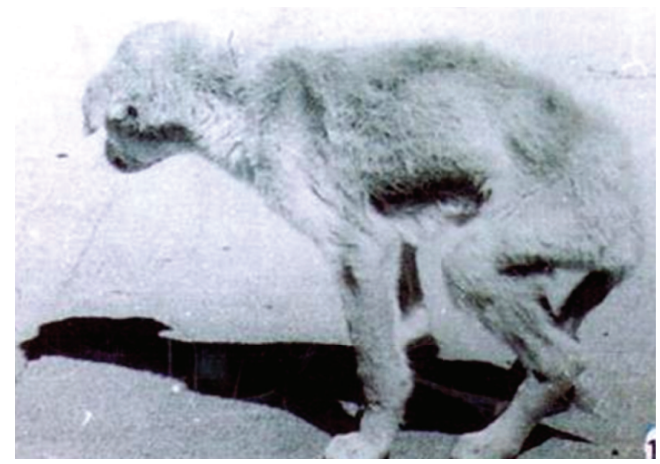

FIgURE 11: A highly emaciated infected dog with T. canis. Note the tucked up abdomen and posterior paralysis.

dystrophic calcification particularly inside the tracts left by the juveniles (Figure 9). In the tunica adventitia, the changes were similar but relatively milder.

The adult gravid females of T. canis collected from 5 different regions of the Indian subcontinent were significantly different in length, diameter, and area (Tables 2 and 3). The experimental pups/dogs, which were fed $\mathrm{L}_{2}$ of $T$. canis via mouse passage (Table 4), exhibited a series of clinical signs, including diarrhea and debility (Figure 11).

On postmortem examination (26-89 DPI), the intestine revealed congestion, oedema, and consolidation in lungs. Microscopically, the liver showed portal hepatitis and vacuolar degeneration of hepatocytes, while the lung depicted interstitial pneumonia (Figure 12). The intestine revealed necrotic enteritis with marked infiltration of lymphocytes and plasma cells in the lamina propria leading to thickening and blunting of villi. There was exfoliation of the lining epithelium of the tips of villi (Figure 13). The crypts of Liberkuhnn showed globlet cells hyperplasia.

\section{Discussion}

Watanabe [5] was the first researcher who succeeded in infecting three rabbits with third-stage larvae of A. stronglina and the recovery percentages were $35 \%, 23.3 \%$, and $20 \%$, respectively. The adult worms were recovered between 40 and

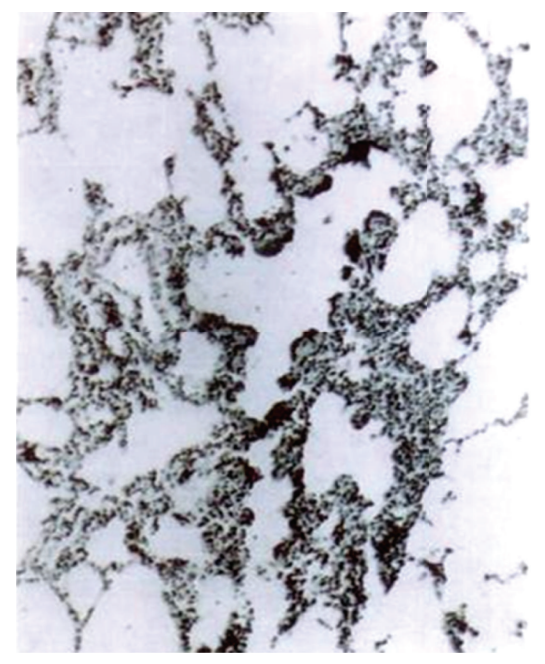

FIGURE 12: Section of lung of T. canis-infected dog depicting interstitial pneumonia $(\mathrm{H}$. E. original magnification $\times 70 \mathrm{X})$.

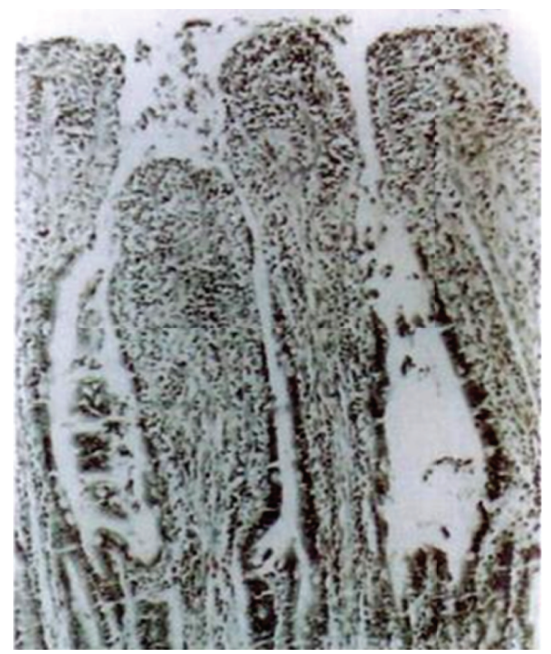

FIGURE 13: Section of intestine of the same dog showing necrotic enteritis and exfoliation of cells (H. E. original magnification $\times 70 \mathrm{X})$.

112 DPI. In the present experiments in 5 rabbits, the recovery was from 36.0 to 45.3 percent, which was much higher in comparison to the earlier study [5]. The recovery of adults from one guinea pig in this study, however, was very low (4\%) and the other guinea pig was negative (Table 1). The prepatent period of $A$. stronglina was found to be 41 days in rabbits. The adult worms recovered from the animals were diminutive in size than the natural host, the pig. From this experiment, it appeared that the rabbit was a good experimental model for A. strongylina infection. Previously, mature adults of $A$. strongylina were collected from wild rodents as second record as a definitive host of this nematode [7].

During experiment with $P$. sexalatus in three rabbits, the $\mathrm{L}_{3}$ of this parasite did not develop to adulthood but became reencapsuled in the gastric wall inducing severe pathological changes, though both parasites, that is, A. strongylina and $P$. sexalatus are known to reside in the stomach of the same 
natural host, that is, the pig. The recovery of an $\mathrm{L}_{3}$ from the omentum could simply be due to erratic migration or due to the effect of biological "incompatibility" between the parasite and its host to avoid host's immune response or due to a more primitive lifestyle it had pursued before it had coaccommodated in its natural host, the pig. Undoubtedly, physiology/ecology and other factors in the stomach of rabbit and pig are unlikely to be similar.

The experiments with the $\mathrm{L}_{3}$ of $S$. lupi revealed that in both rabbits, the larvae not only reencysted in the gastric wall, but also followed the migratory route to the aorta as in natural host that is, dog. In a recent study, ten beagle dogs were experimentally challenged with 40 infectious $S$. lupi larvae orally [8]. These dogs died due to rupture of an aortic aneurism. Seven dogs became infected and presented with esophageal nodules and worm eggs in their feces. One dog did not become infected [8].

The pathological changes induced by the larvae of $P$. sexalatus were rather chronic in nature in the gastric wall than those in the aorta. In the aortic wall the change was more acute, particularly in the tunica media. The development of $S$. lupi both in the gastric wall and its migration to the aortic wall are, therefore, interesting for both "parasitism" and "specificity" of the parasite-host system.

In Russia, ruminants, particularly sheep and cattle may act as normal definitive hosts of the two species, A. strogylina and $P$. saxalatus, whereas, in other parts of the world, these two species are found only in pigs [9]. Phylogenetically rabbit is a herbivore in contrast to guinea pig, which is akin to carnivorous host. Differential development of the two species of these helminth parasites in different regions of the world demonstrates that not only genetic characterization and the variability in their evolution affect their development, but also climatic and ecological factors of the region are responsible for the host specificity. The same holds largely true for $S$. lupi, which is the typical parasite of canines, namely, dog, fox, and jackal, although in the present experimental study, it showed partial development in a herbivore like rabbit.

We presume that significant differences in length, diameter, and area of adult gravid females of T. canis collected from 5 different regions of the Indian subcontinent might be related to the production of more eggs in T. canis. Sonin and Rykovoskii [9] also reported that the longer worms, Ascaris lumbricoides, produced more eggs. However, passage through mice of infective eggs from medium-sized worms (Assam type) and the eventually recovered worms from pups/dogs were found to be reduced in length, which were comparable to small form of local type (Table 3 ). The reduction in length, fecundity and prepatency is known to be influenced by several factors, namely, host's diet, age, size, and immune status, besides space and nutrient quality available in the gut $[10-12]$. This aspect was reviewed by Poulin [13].

After feeding infective larvae of $T$. canis via mouse passage, Herschel [14] determined the prepatent period in dogs to be 34-39 days, almost similar to what recorded in the present study. Most of the infected pups/dogs in the our study (Table 4) developed loss of appetite and diarrhea in early stages, followed by constipation, tucked up abdomen, extreme emaciation, loss of body weight, and gradual weakness in legs or posterior paralysis at later stage (Figure 11). Van Heerdan [15] observed muscular weakness in a dog (adult natural infection) associated with T. canis infection. In the present experiment in dogs, the inflammatory changes observed in the intestine resembled the findings of Litvishko [16], although the severity of lesions was more pronounced. Whether the pathological changes and clinical signs were due to the parasite's passage through mice, variation in the host species, or the strain of parasite is unclear. Zyngier and Santa Rosa [17] and Dunsmore et al. [18] suspected that there may be strain differences in T. canis. Our experiments in mice, rabbits, and monkeys demonstrated acute pathological changes in different organs. An interesting aspect of the study was that in the experimental hosts, the inflammatory response got exaggerated as compared to that reported in natural hosts. The altered pathological response in experimental host may be due to abnormal localization and/or poor adaptation to the tissue microenvironment of experimental/new hosts [13].

\section{Conclusion}

The present study employing several species of nematodes in natural and experimental hosts demonstrated significant variations in the development of the parasite, pathological responses, and host-parasite specificity, which may be of value in understanding the ecology and evolution of parasitism, particularly those having zoonotic importance, namely, T. canis and S. lupi. The study also throws light on the development of pathological lesions vis-a-vis host-parasite interactions.

\section{Conflict of Interests}

The authors declare that there is no conflict of interests regarding the publication of this paper.

\section{Acknowledgments}

The authors gratefully acknowledge the facilities provided by the Dean, College of Veterinary Science, GADVASU, Ludhiana. The authors also thank Dr. Chandrahas, Assistant Professor, Department of Livestock Production and Management for assisting in statistical analysis.

\section{References}

[1] A. E. Keymer and A. F. Read, "The evolutionary biology of parasitism," Parasitology Today, vol. 6, no. 1, pp. 2-3, 1990.

[2] M. Zuk and K. A. McKean, "Sex differences in parasite infections: patterns and processes," International Journal for Parasitology, vol. 26, no. 10, pp. 1009-1023, 1996.

[3] J. E. Alicata, Early Developmental Stages of Nematodes Occurring in Swine, vol. 489, Technical Bulletin, US Department of Agriculture, 1935.

[4] D. A. Porter, "Some new intermediate hosts of the swine stomach worms, Ascarops strongylina and Physocephalus sexalatus," Procedings of Helminthological Society of Washington, vol. 6, pp. 79-80, 1939. 
[5] S. Watanbe, "The intermediate host of swine stomach worm, Ascarops strongylina," 21 Republic Government Experimental Station Animal Hygiene Tokyo, pp. 63-76, 1949.

[6] K. M. Ryzhikov and N. S. Nazarova, "On the reservoir parasitism in Physocephalus sexalatus and Spirocerca lupi," Academy of Sciences, USS R. Works of the Helminthology Laboratory, vol. 9, pp. 249-252, 1959.

[7] S. Ganzorig, N. Batsaikhan, R. Samiya, Y. Morishima, Y. Oku, and M. Kamiya, "A second record of adult Ascarops strongylina (Rudolphi, 1819) (Nematoda: Spirocercidae) in a rodent host," Journal of Parasitology, vol. 85, no. 2, pp. 283-285, 1999.

[8] I. Aroch, S. Harrus, T. Amit et al., "Clinicopathologic findings in an experimental Spirocerca lupi infection in dogs," Israel Journal of Veterinary Medicine, vol. 66, no. 1, pp. 19-25, 2011.

[9] M. D. Sonin and A. S. Rykovoskii, "Chapter: Russia," in Helminths of Wildlife, N. Chowdhury and A. Alonso Aguirre, Eds., Science Publishers, Enfield, NH, USA, 2001.

[10] B. M. Ogilvie and D. J. Hockley, "Effects of immunity of Nippostrongylus brasiliensis adult worms: reversible and irreversible changes in infectivity, reproduction, and morphology," Journal of Parasitology, vol. 54, no. 6, pp. 1073-1084, 1968.

[11] A. Keymer, D. W. T. Crompton, and A. Singhvi, "Mannose and the 'crowding effect' of Hymenolepis in rats," International Journal for Parasitology, vol. 13, no. 6, pp. 561-570, 1983.

[12] M. J. Coyne and G. Smith, "The mortality and fecundity of Haemonchus contortus in parasite-naive and parasite-exposed sheep following single experimental infections," International Journal for Parasitology, vol. 22, no. 3, pp. 315-325, 1992.

[13] R. Poulin, "The evolution of life history strategies in parasitic animals," Advances in Parasitology, vol. 37, pp. 107-134, 1996.

[14] A. M. Herschel, "The behavior in the dog (Beagle) of larvae of Toxocara canis (Anisakidae) taken from paratenic hosts," Dissert Tiergt Hochsch Hannover, pp. 66, 1981.

[15] J. Van Heerden, "Muscular weakness in a dog associated with severe roundworm infestation," Journal of the South African Veterinary Association, vol. 54, no. 2, pp. 133-134, 1983.

[16] N. T. Litvishko, "Tissue changes in the intestine of dogs during larval migration of Toxocara canis," Trudi Kharkovsk Veterinar Instituta, vol. 20, pp. 177-185, 1949.

[17] F. R. Zyngier and G. Santa Rosa, "Multiple infection with Toxocara canis. Influence of antihistamines and corticosteroids on the histopathological response," Annals of Tropical Medicine and Parasitology, vol. 70, no. 4, pp. 445-448, 1976.

[18] J. D. Dunsmore, R. C. A. Thompson, and I. A. Bates, "The accumulation of Toxocara canis larvae in the brains of mice," International Journal for Parasitology, vol. 13, no. 5, pp. 517-521, 1983. 

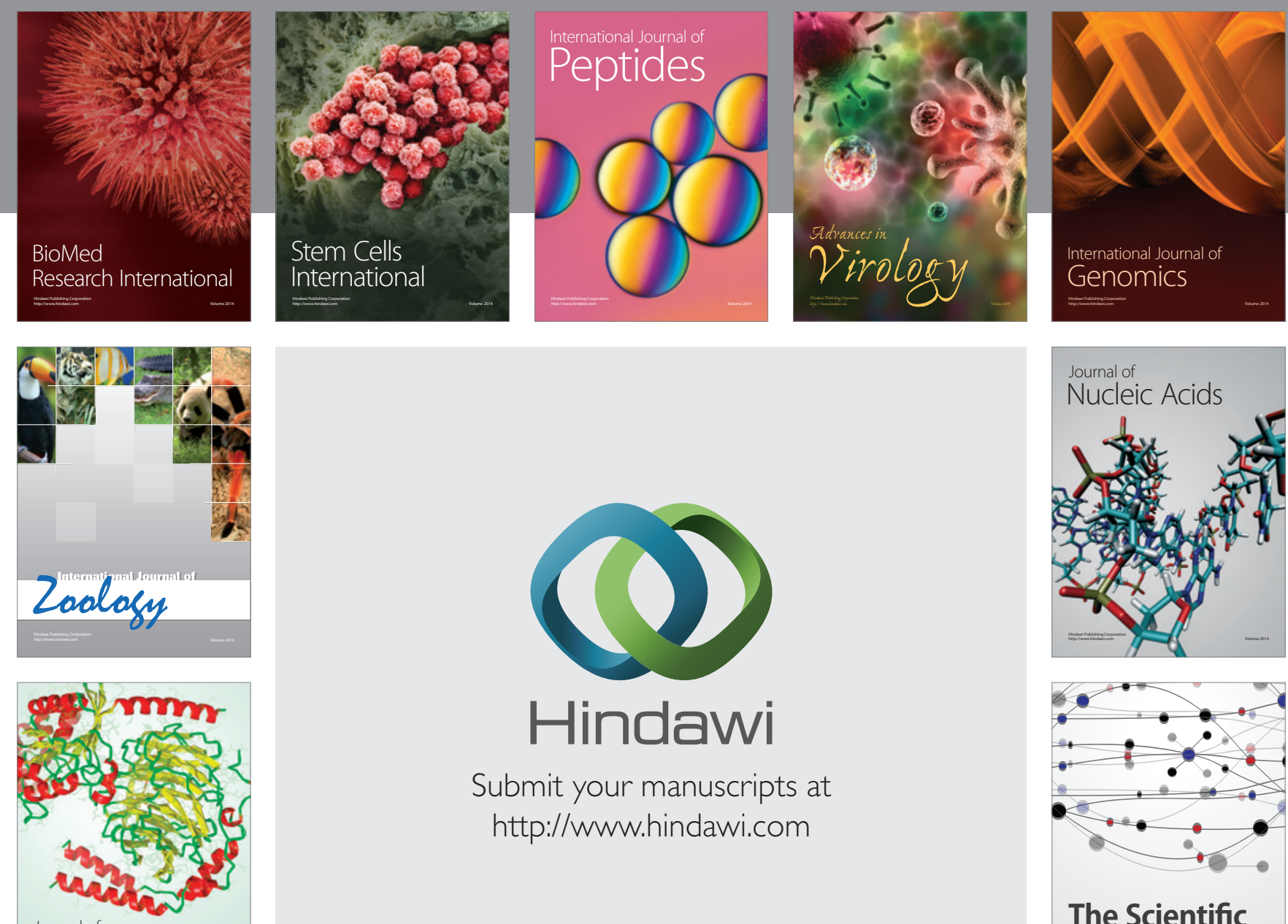

Submit your manuscripts at

http://www.hindawi.com

Journal of
Signal Transduction
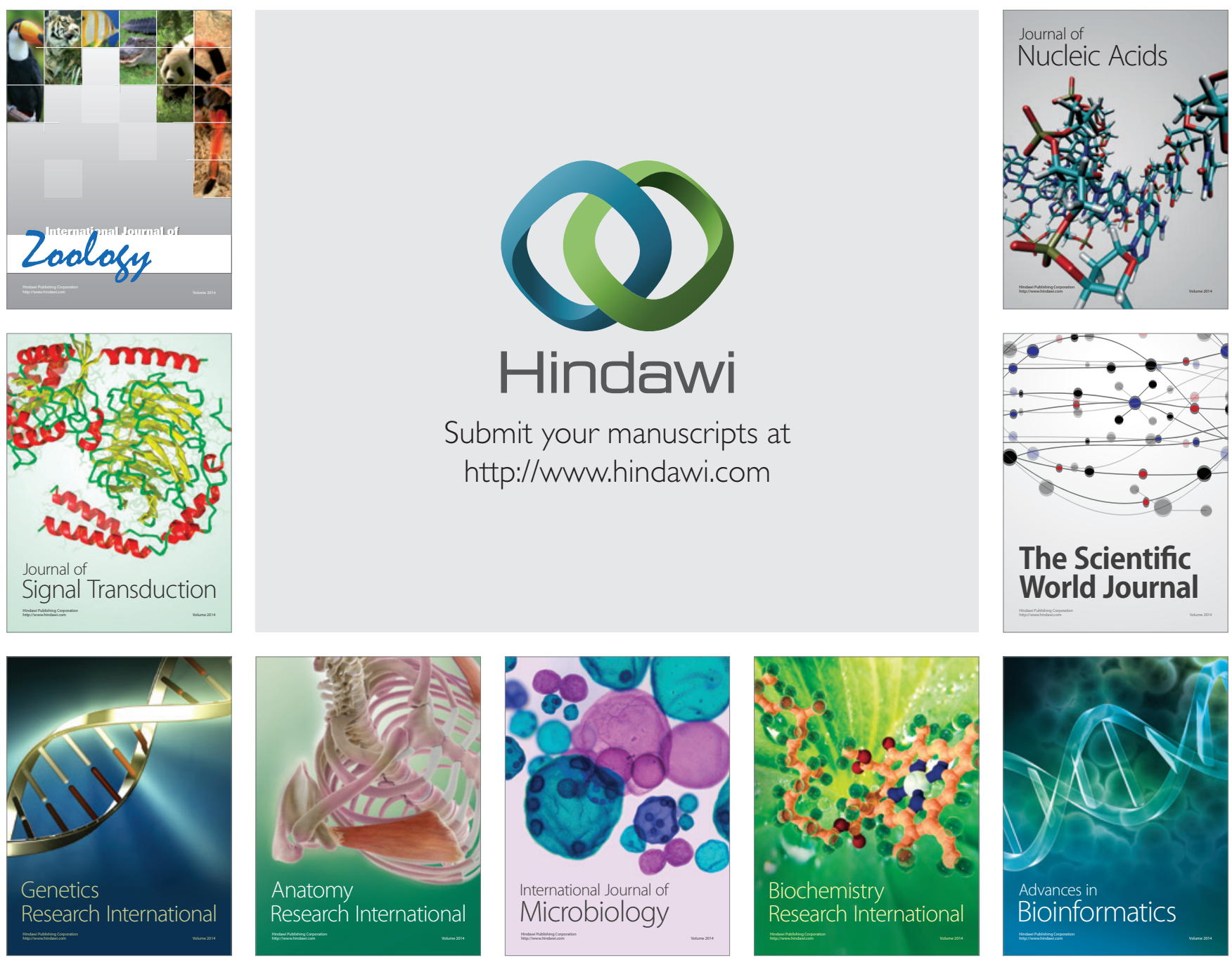

The Scientific World Journal
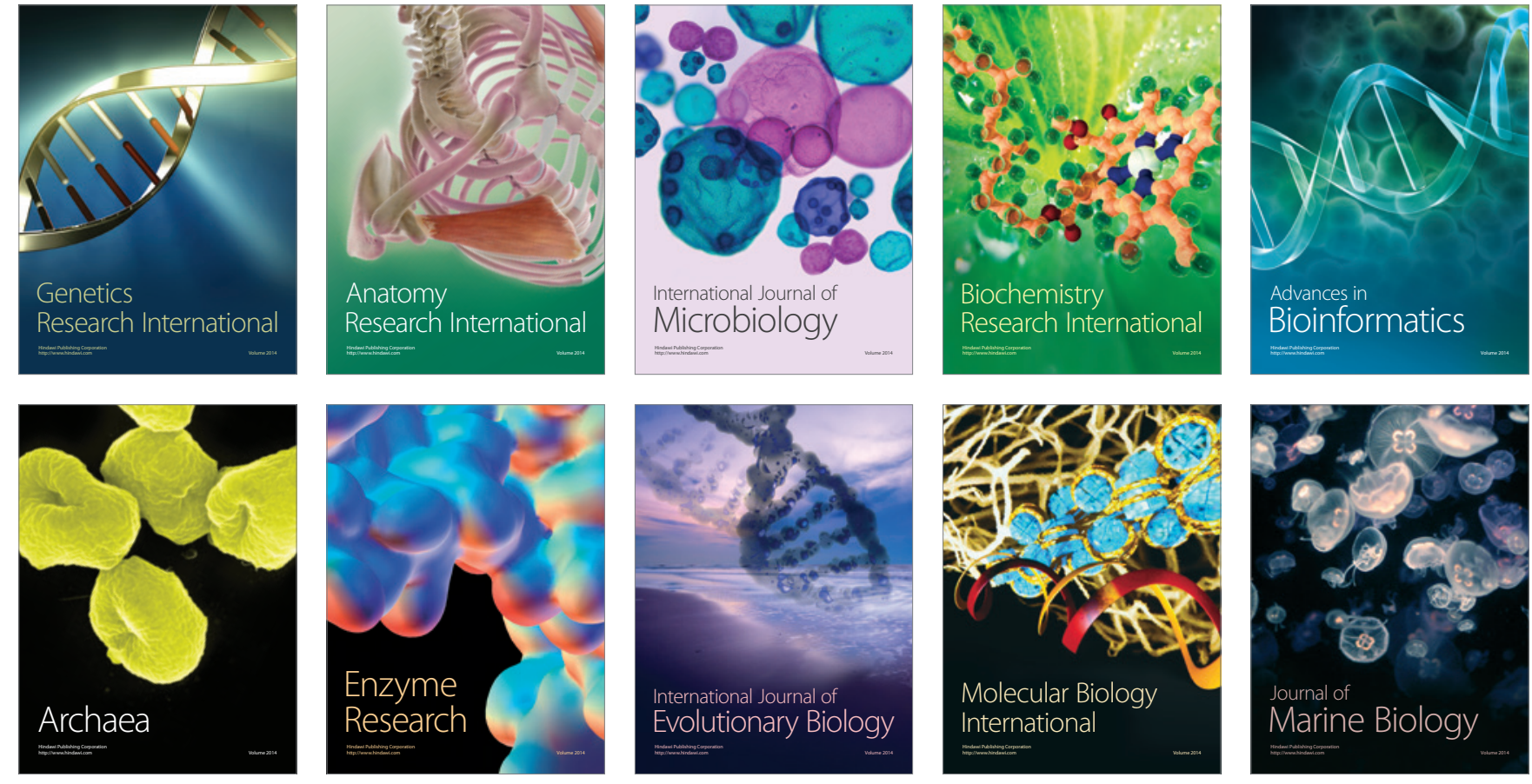